\title{
Angelica sinensis Suppresses Body Weight Gain and Alters Expression of the FTO Gene in High-Fat-Diet Induced Obese Mice
}

\author{
Tao Zhong, Xiao-Yue Duan, Hao Zhang, Li Li, Hong-Ping Zhang, and Lili Niu
}

Farm Animal Genetic Resources Exploration and Innovation Key Laboratory of Sichuan Province, College of Animal Science and Technology, Sichuan Agricultural University, Chengdu 611130, China

Correspondence should be addressed to Lili Niu; niulili@sicau.edu.cn

Received 7 April 2017; Revised 12 June 2017; Accepted 24 July 2017; Published 20 September 2017

Academic Editor: Ming D. Li

Copyright (C) 2017 Tao Zhong et al. This is an open access article distributed under the Creative Commons Attribution License, which permits unrestricted use, distribution, and reproduction in any medium, provided the original work is properly cited.

\begin{abstract}
The root of Angelica sinensis (RAS) is a traditional Chinese medicine used for preventing and treating various diseases. In this study, we assessed RAS supplementation effects on body weight and the FTO gene expression and methylation status in a high-fat-diet (HFD) induced obese mouse model. Female obese mice were divided into groups according to RAS dosage in diet as follows: normal diet, HFD diet (HC), HFD with low-dosage RAS (DL), HFD with medium-dosage RAS (DM), and HFD with high-dosage RAS (DH). After RAS supplementation for 4 weeks, body weight suppression and FTO expression in DH mice were significantly higher than in HC mice, whereas no significant change in FTO expression was detected between DM and DL mice or in their offspring. Bisulfite sequencing PCR (BSP) revealed that the CpG island in the FTO promoter was hypermethylated up to $95.44 \%$ in the HC group, $91.67 \%$ in the DH group, and $90.00 \%$ in the normal diet group. Histological examination showed that adipocytes in the DH group were smaller than those in the HC group, indicating a potential role of RAS in obesity. This study indicated that RAS could ameliorate obesity induced by HFD and that the molecular mechanism might be associated with the expression of the FTO gene.
\end{abstract}

\section{Introduction}

Obesity is a global health priority and resistance to diet induced obesity has been studied in many animal models. A diet rich in sugar and containing up to $45 \%$ fat has been widely used to induce obesity in mice [1-3]. Scientists have found that some Chinese herbs like berberine, curcuma longa, and Sibiraea angustata could effectively ameliorate obesity by inhibiting the synthesis, growth, and accumulation of fatty acid in adipocytes [4-6]. The functions of Chinese herbs have been investigated in vivo in mouse models of highfat-diet (HFD) induced obesity [7].

The root of Angelica sinensis (Chinese named Danggui), a well-known herbal medicine, has been historically used as a tranquilizer or a tonic agent $[8,9]$. As a functional food, RAS can also be used for the amelioration of inflammation, diabetes, and cardiovascular disorders. Previous studies have shown that the Angelica sinensis polysaccharide (ASP), the active chemical components of RAS, had hematopoietic effects in animal and cellular models [10]. Two acidic polysaccharides (APS-3b and APS-3c) significantly inhibited the growth of S180 tumors and increased the life span of S180 tumor-bearing mice [11]. Furthermore, the antioxidant effects of ASP could stimulate the endothelial production of nitric oxide and resist ischemia/reperfusion (I/R) injury [12].

The fat mass and obesity associated (FTO) gene has a relative effect on obesity [13]. FTO is located on chromosome 16 in humans and encodes a protein with a double-stranded b-helix fold, homologous to the members of the nonheme and 2-oxoglutarate oxygenase superfamily (which mainly impact the metabolism of fatty acid) [14]. Further, studies in humans and rodents suggested that FTO is involved in food intake regulation and lipid metabolism [15]. Histological studies revealed that the localization of FTO mRNA and protein in the hypothalamic nucleus was of critical importance in the regulation of feed intake in mice [16]. Loss of function of FTO in mice led to postnatal growth retardation and a significant reduction in adipose tissue and lean body mass [17]. Over 
expression of FTO, however, led to a dose-dependent increase in body and fat mass [18]. Furthermore, Merkestein and colleagues found that FTO influences adipogenesis by regulating the process of mitotic clonal expansion in obese mice [19].

In the present study, we assessed the effects of RAS supplementation on body weight in HFD mice. Furthermore, mRNA expression and promoter methylation status of the FTO gene were determined to compare the effects of RAS between control and treated groups. This study will provide a foundation for understanding the functions of RAS in obesity resistance.

\section{Materials and Methods}

2.1. Ethics Statement. Animas involved in this study were sacrificed according to the Regulations for the Administration of Affairs Concerning Experimental Animals and approved by the Institutional Animal Care and Use Committee at the College of Animal Science and Technology, Sichuan Agricultural University, Sichuan, China, under the permit number DKY-B20110807.

2.2. Animals and Diets. Female KM mice at 5 weeks of age were obtained from the Chengdu Dossy Laboratory Animal Co., Ltd, in Sichuan province, China. Mice were reared at standard conditions within a free access to food and water for 1 week to acclimatize to experimental conditions. Mice were then randomly assigned to the normal diet group (GC, $n=$ 10 ) or the HFD group (HC, $n=48$ ) without RAS supplementation. After 5 weeks, the obese mice were randomly divided into four groups. All groups were continually fed with HFD. The first group ( $n=12$ ) was designated the high-fat control group (HC) without RAS supplementation. The second group $(n=11)$ received RAS supplementation at $2.00 \mathrm{~g} / \mathrm{kg} \cdot \mathrm{BW}$ and was designated as the low-dose group (DL). The third group $(n=11)$ received RAS supplementation at $5.00 \mathrm{~g} / \mathrm{kg} \cdot \mathrm{BW}$ and was designated the medium-dose group (DM) and the last group ( $n=12$ ) was designated the high-dose group (DH) with RAS supplementation at $10.00 \mathrm{~g} / \mathrm{kg}$.BW. The female offspring were obtained by mating with the male KM fed under same conditions for each group. The diet formula is shown in Table 1. The RAS was dried and ground and then added to the mixture, which was kneaded and made into a cylindrical shape using 5-mL injectors. Finally, the mixture was dried at $60^{\circ} \mathrm{C}$ overnight and stored in a hermetic bag after cooling to room temperature. Body weight was measured weekly. Adipose tissues were collected from 4 mice in each group after RAS supplementation for 35, 60, and 95 days.

2.3. Total RNA Extraction and Reverse Transcription. Mice were sacrificed by cervical dislocation and adipose tissue was collected and rapidly frozen in liquid nitrogen and then stored at $-80^{\circ} \mathrm{C}$. Total RNA was extracted using TRIzol reagent (Invitrogen, CA, USA). The purity of the isolated RNA was determined by agarose gel electrophoresis and the concentration was quantified by the ND-2000 Nanodrop (Thermo Scientific, MA, USA). cDNA was synthesized using the Prime Script RT reagent Kit (Takara, Dalian, China) according to the manufacturer's recommendations.

2.4. Quantitative Real-Time PCR of the FTO Gene. We performed quantitative real-time PCR (qPCR) to quantify the relative mRNA expression levels of FTO in adipose tissues of mice from GC, HC, DL, DM, and DH groups, as well as DH offspring. Primer pairs used for qPCR (Table 2) were designed according to the mouse FTO gene (NM_011936). The qPCR was performed in triplicate using a SYBR ${ }^{\circledR}$ Premix Ex Taq $^{\mathrm{TM}}$ II kit (Takara, Dalian, China). Each qPCR reaction (total volume $10 \mu \mathrm{L}$ ) contained $0.8 \mu \mathrm{L}$ cDNA, $5 \mu \mathrm{L}$ SYBR Green II, $0.8 \mu \mathrm{L}$ primer pairs, and $3.4 \mu \mathrm{L} \mathrm{dd}_{2} \mathrm{O}$. The $\mathrm{qPCR}$ procedures were as follows: $95^{\circ} \mathrm{C}$ for $3 \mathrm{~min}, 40$ cycles of $95^{\circ} \mathrm{C}$ for $10 \mathrm{~s}, 30 \mathrm{~s}$ at optimum temperatures, $72^{\circ} \mathrm{C}$ for $10 \mathrm{~s}$, and a final extension for $5 \mathrm{~min}$, and then a temperature increment of $0.5^{\circ} \mathrm{C} / \mathrm{s}$ from $65^{\circ} \mathrm{C}$ to $95^{\circ} \mathrm{C}$ to build a melting curve. The specificity of qPCR products was confirmed by melting curve analysis. The relative expression of FTO mRNA was determined using the geometric mean of GAPDH, $\beta$-actin, and $18 s$ rRNA by the $2^{-\Delta \Delta \mathrm{CT}}$ method [20].

2.5. DNA Preparation and Methylation Analysis by BSP Method. Genomic DNA was extracted from the adipose tissues of mice from GC, HC, and DH groups after RAS supplementation for 35 days, using TIANamp Genomic DNA Kit (Tiangen, Beijing, China). Three animals were randomly selected from each group. DNA was quantified by the ND2000 Nanodrop and then treated with sodium bisulfite using the EZ DNA Methylation Gold Kit (Zymo Research, CA, USA). Following the manufacturer's instructions, DNA dosage was strictly limited to insure complete cytosine to uracil conversion.

The methylated CpGs in the FTO promoter (Acc. number AC105989) were estimated by the online program (http://www.urogene.org/cgi-bin/methprimer/methprimer. cgi). The primer pairs were modified by Primer Premier 5 (Table 2). The PCR was run on a C1000 PCR system Thermocycler (Bio-Rad, Richmond, CA) in a volume of $30 \mu \mathrm{L}$ including $1 \mu \mathrm{L}$ bisulfite-converted DNA or $0.5 \mu \mathrm{L}$ PCR products, $15 \mu \mathrm{L}$ Zymo $\mathrm{Taq}^{\mathrm{TM}}$ PreMix, or $1 \mu \mathrm{L}$ primer pairs. PCR reactions were as follows: $95^{\circ} \mathrm{C}$ for $5 \mathrm{~min}, 40$ cycles of $30 \mathrm{~s}$ at $95^{\circ} \mathrm{C}, 30 \mathrm{~s}$ at $65.2^{\circ} \mathrm{C}$ (second round: $57.5^{\circ} \mathrm{C}$ ), and $30 \mathrm{~s}$ at $72^{\circ} \mathrm{C}$, and a final extension for $7 \mathrm{~min}$ at $72^{\circ} \mathrm{C}$. The second PCR products were purified with a DNA Gel Extraction Kit (TsingKe, Chengdu, China) and then ligated into pMD 19-T vector (Takara, Dalian, China). At least ten positive recombinants were sequenced on an ABI 3730XL DNA analyzer (Applied Biosystems, USA). The methylated CpGs were analyzed with the QUantification tool (QUMA, http://quma.cdb.riken.jp/).

2.6. Histological and Morphometric Analysis. The abdominal adipose tissues were resected and fixed in $4 \%$ paraformaldehyde after washing. They were then dehydrated in ethanol and soaked in dimethylbenzene and then embedded in paraffin. The tissue blocks were sectioned at 4-micron thickness and then stained with haematoxylin and eosin $(\mathrm{H} \& \mathrm{E})$ reagent. 
TABLE 1: Composition of the experimental diets used in the present study.

\begin{tabular}{|c|c|c|c|c|c|}
\hline \multirow{2}{*}{ Ingredients } & \multirow{2}{*}{$\begin{array}{c}\text { Normal diet } \\
\text { GC }\end{array}$} & \multicolumn{4}{|c|}{ High-fat-diet } \\
\hline & & $\mathrm{HC}$ & $\mathrm{DL}$ & $\mathrm{DM}$ & $\mathrm{DH}$ \\
\hline Corn starch & $30.0 \%$ & $22.0 \%$ & $21.6 \%$ & $21.0 \%$ & $19.6 \%$ \\
\hline Flour & $30.0 \%$ & $22.0 \%$ & $21.6 \%$ & $21.0 \%$ & $19.6 \%$ \\
\hline Bran & $14.0 \%$ & $10.0 \%$ & $10.0 \%$ & $9.6 \%$ & $9.0 \%$ \\
\hline Soybean meal & $20.0 \%$ & $15.0 \%$ & $14.8 \%$ & $14.4 \%$ & $13.4 \%$ \\
\hline Fish meal & $6.0 \%$ & $6.0 \%$ & $6.0 \%$ & $5.6 \%$ & $5.0 \%$ \\
\hline Lard & 0 & $8.0 \%$ & $7.8 \%$ & $7.6 \%$ & $7.4 \%$ \\
\hline Egg & 0 & $10.0 \%$ & $10.0 \%$ & $9.6 \%$ & $9.0 \%$ \\
\hline Sucrose & 0 & $7.0 \%$ & $6.8 \%$ & $6.6 \%$ & $6.2 \%$ \\
\hline Angelica sinensis & 0 & 0 & $1.4 \%$ & $4.6 \%$ & $10.8 \%$ \\
\hline Total & $100.0 \%$ & $100.0 \%$ & $100.0 \%$ & $100.0 \%$ & $100.0 \%$ \\
\hline
\end{tabular}

TABLE 2: Information of primer pairs used in this study.

\begin{tabular}{|c|c|c|c|}
\hline Primer name & Primer sequence $\left(5^{\prime}-3^{\prime}\right)$ & Size (bp) & $\operatorname{Tm}\left({ }^{\circ} \mathrm{C}\right)$ \\
\hline \multicolumn{4}{|l|}{ QPCR } \\
\hline FTO-Q-1F & GAGTTCTATCAGCAGTGG & \multirow{2}{*}{163} & \multirow{2}{*}{55.0} \\
\hline FTO-Q-1R & GCACATCTTTGCCTTGGA & & \\
\hline GAPDH-1F & GGTGAAGGTCGGTGTGAACG & \multirow{2}{*}{233} & \multirow{2}{*}{55.0} \\
\hline GAPDH-1R & CTCGCTCCTGGAAGATGGTG & & \\
\hline ACTB-1F & CGTTGACATCCGTAAAGACC & \multirow{2}{*}{281} & \multirow{2}{*}{55.0} \\
\hline ACTB-1R & AACAGTCCGCCTAGAAGCAC & & \\
\hline 18S rRNA-1F & AGGGGAGAGCGGGTAAGAGA & \multirow{2}{*}{241} & \multirow{2}{*}{55.0} \\
\hline 18S rRNA-1R & GGACAGGACTAGGCGGAAC & & \\
\hline \multicolumn{4}{|l|}{ BPS } \\
\hline FTO-B1F & TAGTTGATTTTGTTTGAAGAGGAAGA & \multirow{2}{*}{671} & \multirow{2}{*}{65.2} \\
\hline FTO-B1R & TCСТАСТСАСТАТСААСААТТССТАА & & \\
\hline FTO-B2F & GGGTTGAAGAGGTGGTTTAGTAGTTA & \multirow{2}{*}{496} & \multirow{2}{*}{57.5} \\
\hline FTO-B2R & АСААТСТСАСТСААТССАСТТАСАТСТ & & \\
\hline
\end{tabular}

Photomicrographs were obtained and analyzed using ImagePro Plus software (Media Cybernetics).

2.7. Statistical Analyses. All of the statistical analyses were performed using SPSS 20.0 (SPSS, Chicago, IL, USA) and the data were represented as means \pm SD. The significance between groups was estimated by a one-way ANOVA test and Student's $t$-test.

\section{Results}

3.1. Effects of RAS Supplementation on Body Weight in HFD Fed Mice. Compared with the normal diet group (GC), the HC mice showed marked obesity after feeding with HFD for 5 weeks (Figure 1(a)). During HFD treatment, appetite, activity, and coat luster were normal for all animals. After 5 weeks, the mice in the HC group were divided into five subgroups, $\mathrm{HC}, \mathrm{DL}, \mathrm{DM}$, and $\mathrm{DH}$, fed with different dosage of RAS supplementation for another 4 weeks. Compared with the mice in the GC, HC, DL, and DM groups, the mice in the $\mathrm{DH}$ group showed the lowest weight gain (Figure 1(b) and Table 3). We later used $10.00 \mathrm{~g} / \mathrm{kg} \cdot \mathrm{BW}$ RAS to feed $\mathrm{DH}$ offspring continually. However, RAS supplementation did not show an obvious effect on body weight between the offspring from the $\mathrm{HC}$ and DH groups (data not shown).

3.2. Effects of RAS Supplementation on FTO mRNA Expression. To assess the effects of RAS supplementation on FTO mRNA expression, we performed qPCR to quantify FTO expression in adipose tissues collected from mice in the GC, $\mathrm{HC}, \mathrm{DL}, \mathrm{DM}$, and DH groups at days 35 and 60. In addition, we also determined FTO expression in $\mathrm{HC}$ and $\mathrm{DH}$ mice at day 95, as well as in their progeny at day 35. The qPCR results showed that the expression of FTO in the RAS-supplemented groups (DL, DM, and DH) was significantly higher than in the HC group after both $35 \mathrm{~d}$ and $60 \mathrm{~d}$ (Figures 2(a) and 2(b)). No significant difference was detected between the $\mathrm{HC}$ and $\mathrm{DH}$ groups after $90 \mathrm{~d}$ (Figure 2(c)). Moreover, there was no significant difference in FTO expression between the offspring of mice in the HC and DH groups (Figure 2(d)).

3.3. Effects of RAS Supplementation on Methylation in the FTO Promoter. The structure of the analyzed CpG sites and their locations (GenBank Acc. number AC105989: 31474-31968) 


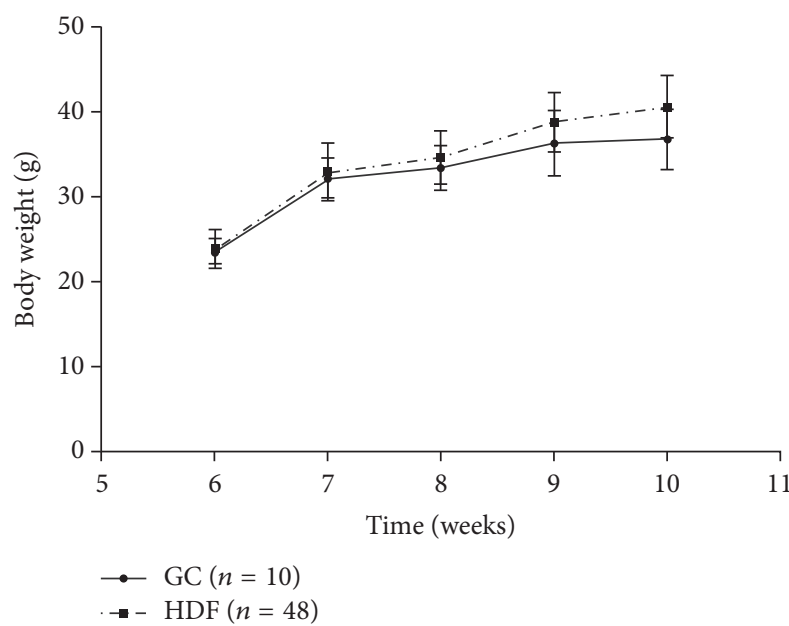

(a)

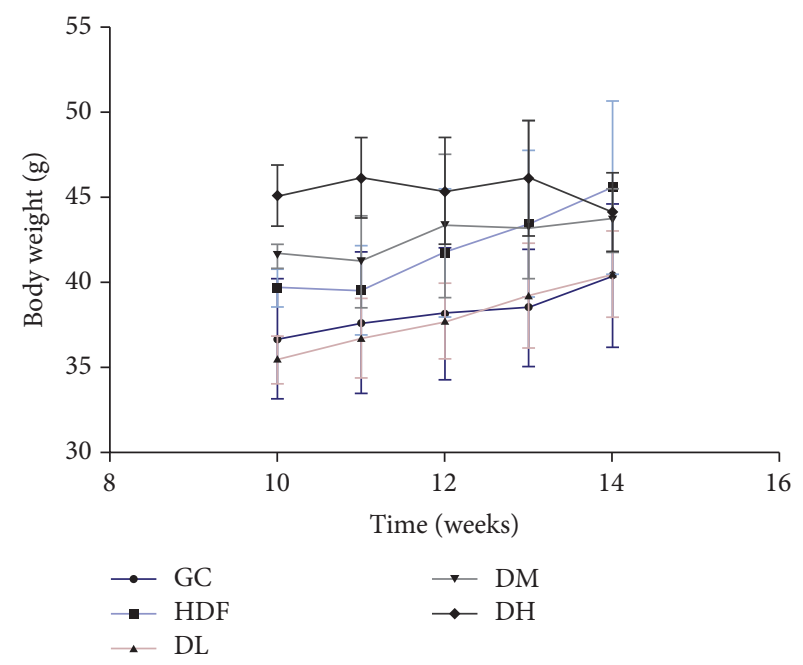

(b)

FIGURE 1: Body weight changes in the HFD mice model (a). Effects of RAS supplementation on body weight alterations in the HFD mice (b).

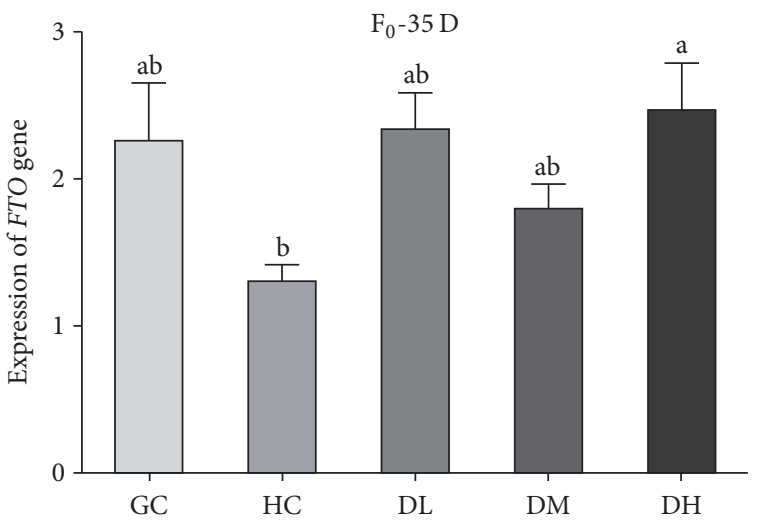

(a)

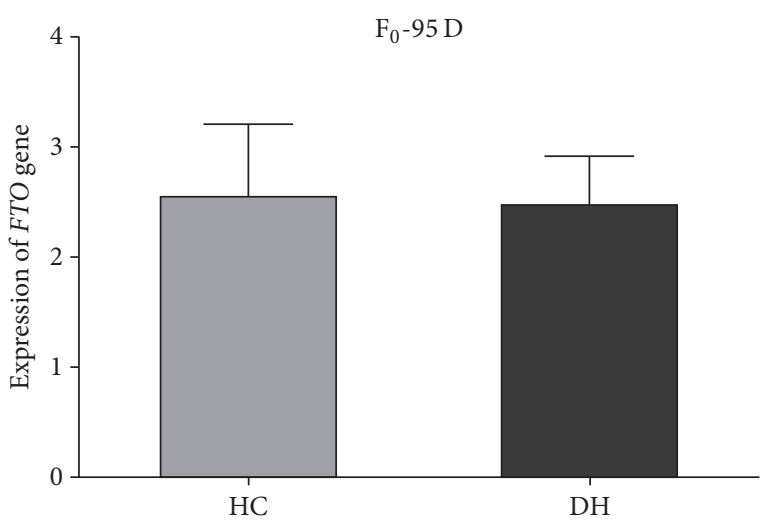

(c)

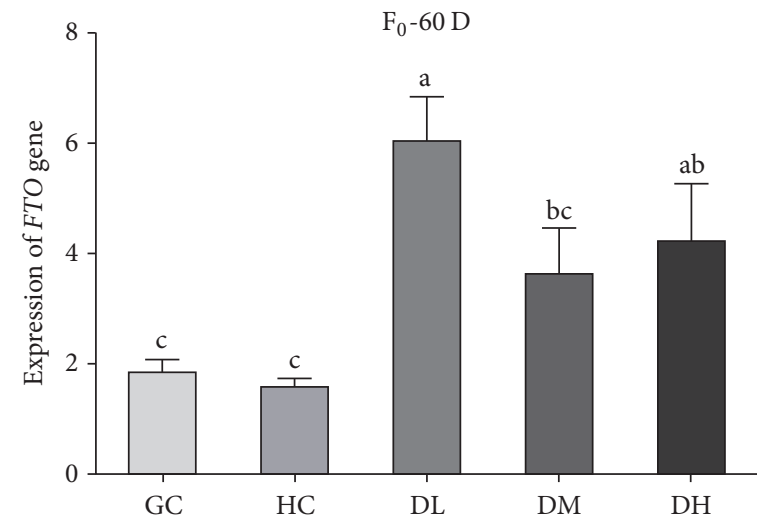

(b)

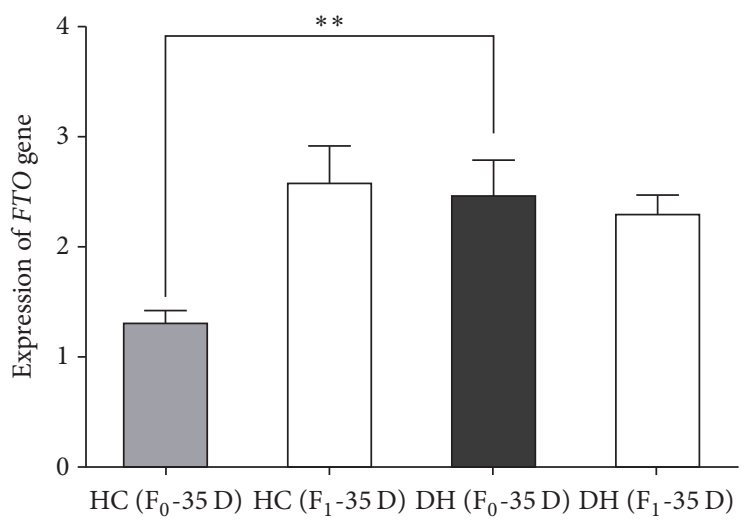

(d)

FIgURE 2: Effects of RAS supplementation on FTO mRNA expression in HFD obese mice. Different letters above each bar represent being significantly different $(P<0.05) . * *$ indicates significant difference $(P<0.01)$. 


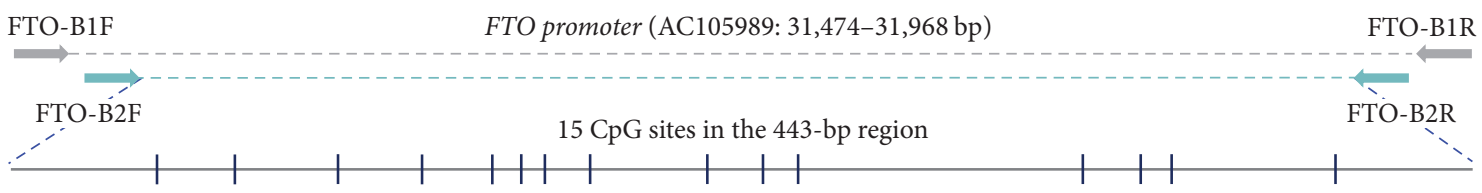

(a)

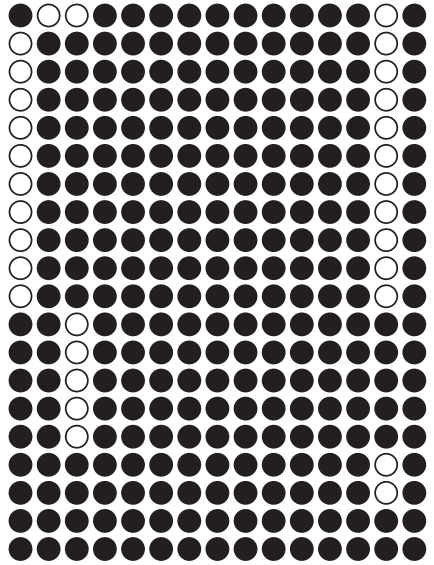

GC $90.00 \%$

Methylated

$\bigcirc$ Unmethylated

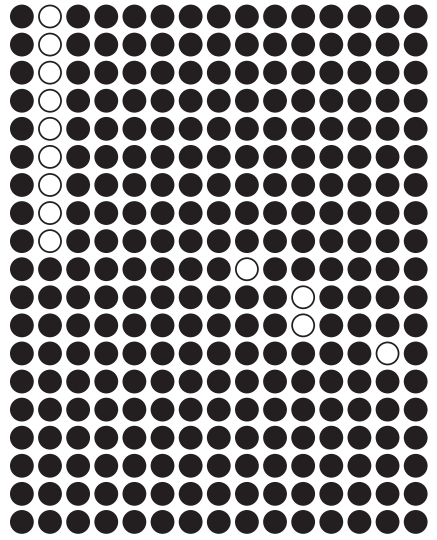

HC $95.44 \%$

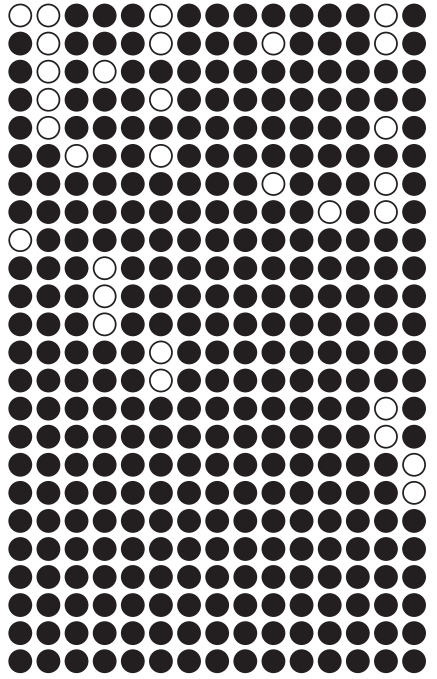

DH $91.67 \%$

(b)

FIgURE 3: Schematic representation of the FTO promoter and the intragenic CpG sites in a 443-bp region (a). Methylation status of the FTO promoter in adipose tissues in GC, HC, and DH mice after being RAS-treated for 35 days (b). Each line represented as a sequence from each clone, while each vertical bar corresponded to an identical CpG site.

within the FTO gene are shown in Figure 3. The DNA methylation patterns of the GC, $\mathrm{HC}$, and $\mathrm{DH}$ groups were assessed by bisulfite sequencing. The region analyzed includes a defined $\mathrm{CpG}$ island, located $666 \mathrm{bp}$ upstream of the start codon. The FTO gene was hypermethylated in GC mice (90.00\%), while the mice fed with HFD showed a higher methylation level in the HC group (95.44\%). As expected, supplementation of RAS reduced the methylation level, which reached $91.67 \%$ in DH mice.

3.4. Effects of RAS Supplementation on Adipocyte Morphology. The H\&E histological examination showed that adipocytes had a polygonal morphology with typical peripherally located nuclei and distinct cell borders (Figure 4(a)). After being fed HFD with RAS supplementation for $35 \mathrm{~d}$, the volume of adipocytes in the $\mathrm{DH}$ group was smaller than that in the $\mathrm{HC}$ group and showed some fibrous tissue in the intercellular substance and a greater number of adipocytes (Figure 4(a)). Adipocytes in DH mice fed RAS for $60 \mathrm{~d}$ were smaller again and the cell arrangement was obviously abnormal compared with $\mathrm{HC}$ mice. Histological and quantitative analyses revealed that the mean diameter of adipocytes in the $\mathrm{HC}$ and DH mice fed RAS for $35 \mathrm{~d}$ was $373.9 \pm 64.8 \mu \mathrm{m}$ and $227.7 \pm 48.2 \mu \mathrm{m}$, respectively, and adipocyte area was $115,817.8 \pm 38,956.0 \mu \mathrm{m}^{2}$ and 44,655.3 $\pm 19,589.2 \mu \mathrm{m}^{2}$, respectively (Figure $4(\mathrm{~b})$ ). In the $\mathrm{DH}$ mice fed RAS for $60 \mathrm{~d}$, the mean diameter and area of adipocytes were $171.4 \pm 66.0 \mu \mathrm{m}$ and 27,303.4 \pm $20,430.6 \mu \mathrm{m}^{2}$, respectively. Overall, the mean diameter and area of adipocytes in $\mathrm{HC}$ mice were significantly greater than in $\mathrm{DH}$ mice $(P<0.05)$.

\section{Discussion}

In this report we demonstrate, for the first time, the favorable effects of RAS supplementation on body weight, gene expression, and promoter methylation of the FTO gene in mice with HFD obesity. As many previous studies, the obesity mouse model was induced by HFD; while formulas differ between studies, common ingredients included sugar and lard $[1,2]$. The obesity mice model was established by HFD and the standard deviation both in GC and HC groups was accredited. Intragroup inconsistencies in body weight after the administration of RAS may have been due to individual error $[8,21]$. In the present study, body weight gain was lowest in the $\mathrm{DH}$ group, which received $10.00 \mathrm{~g} / \mathrm{kg} \cdot \mathrm{BW}$ of RAS supplementation (Table 3). Meanwhile, body weight gain in the mice fed with low or moderate dosage (DL and DM groups) was not different from the HC mice, indicating that a higher dosage of RAS supplementation $(10.00 \mathrm{~g} / \mathrm{kg} \cdot \mathrm{BW})$ 


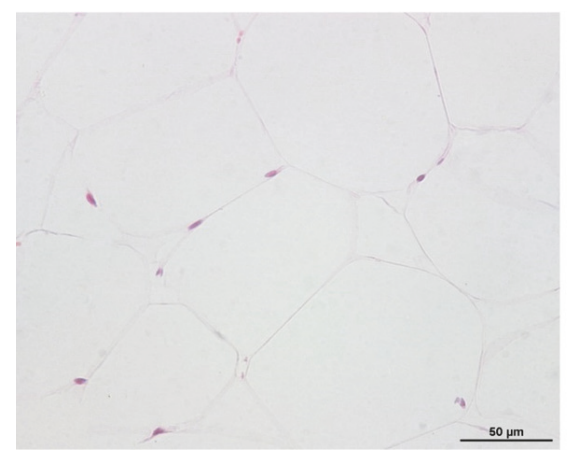

HC (35 d)

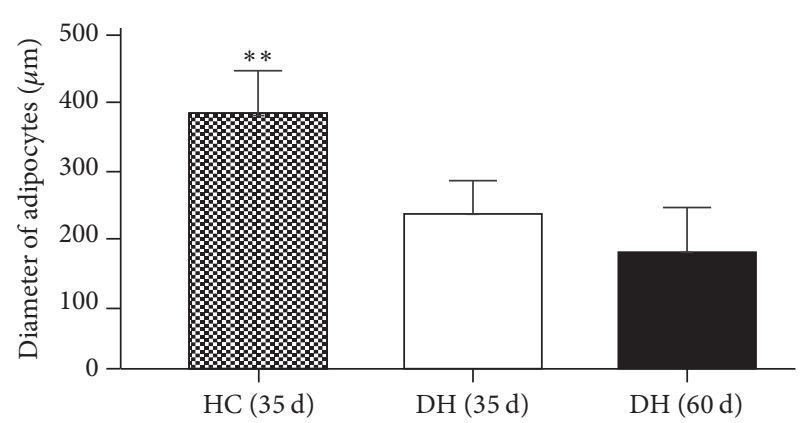

(b)

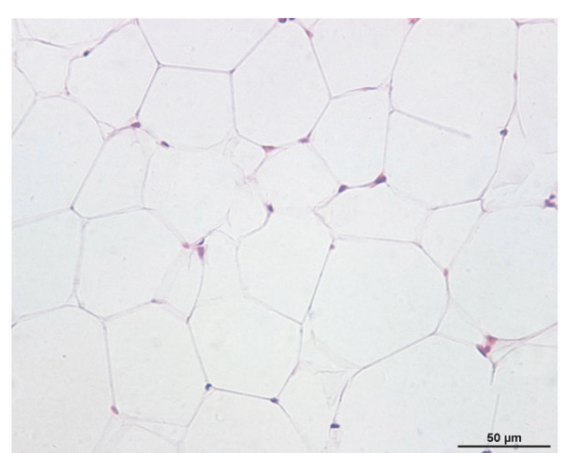

DH (35 d)

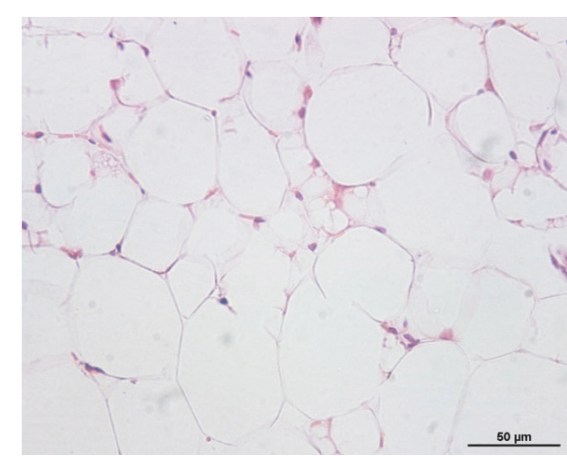

DH $(60 \mathrm{~d})$

(a)

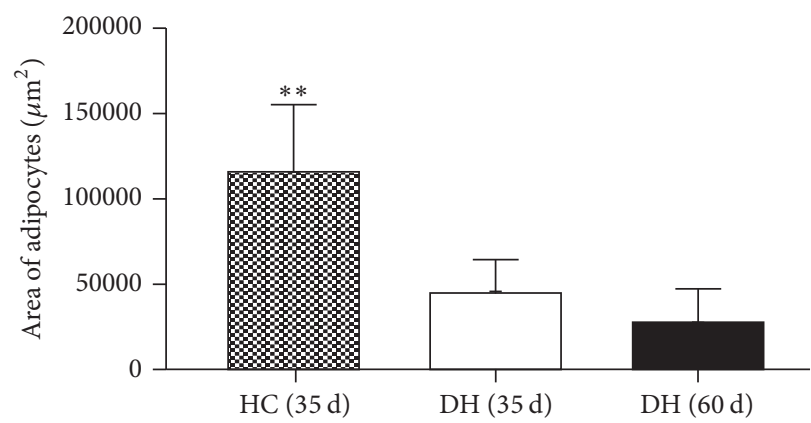

(c)

Figure 4: Histological assessment of the adipose tissues of mice in the HC and DH groups (a). Scale bars, $50 \mu \mathrm{m}$. The quantitative data of the mean diameter and area of adipocytes are shown (b). Values are mean $\pm \mathrm{SD}(n=3)$. ${ }^{* *} P<0.01$.

TABLE 3: Effects of RAS supplementation on body weight alterations in mice.

\begin{tabular}{lccccccc}
\hline Group & AS content* & Sample size & 10 weeks & 11 weeks & 12 weeks & 13 weeks & 14 weeks \\
\hline GC & NA & 10 & $36.70 \pm 3.52$ & $37.62 \pm 4.14$ & $38.16 \pm 3.90$ & $38.50 \pm 3.43$ & $40.40 \pm 4.20$ \\
HC & NA & 12 & $39.71 \pm 1.13$ & $39.57 \pm 2.62$ & $41.75 \pm 3.75$ & $43.46 \pm 4.32$ & $45.60 \pm 5.08$ \\
DL & $2.00 \mathrm{~g} / \mathrm{kg} \cdot \mathrm{BW}$ & 11 & $35.50 \pm 1.43$ & $36.74 \pm 2.32$ & $37.72 \pm 2.22$ & $39.24 \pm 3.09$ & $40.50 \pm 2.53$ \\
DM & $5.00 \mathrm{~g} / \mathrm{kg} \cdot \mathrm{BW}$ & 11 & $41.60 \pm 0.65$ & $41.26 \pm 2.71$ & $43.34 \pm 4.20$ & $43.17 \pm 2.92$ & $43.70 \pm 1.85$ \\
DH & $10.00 \mathrm{~g} / \mathrm{kg} \cdot \mathrm{BW}$ & 12 & $45.10 \pm 1.80$ & $46.15 \pm 2.37$ & $45.38 \pm 3.14$ & $46.14 \pm 3.37$ & $44.20 \pm 2.27$ \\
\hline
\end{tabular}

*The dosage of AS was according to the recommendation.

might be more beneficial in suppressing body weight in obese individuals.

We found that the expression of FTO mRNA was significantly increased in RAS-supplemented mice (DL, DM, and $\mathrm{DH}$ groups) and body weight gain of $\mathrm{HC}$ mice was markedly higher than that of DL, DM, and DH mice. This suggests that RAS might influence BW gain via alterations of gene expression. As showed by qPCR, there was a significant difference in FTO expression between RAS-supplemented groups and the GC and $\mathrm{HC}$ groups in $35 \mathrm{~d}$, suggesting a correlation between FTO expression and body weight gain. In $\mathrm{HC}$ mice, however, FTO expression was lowest and obesity was highest. Previous studies reported that loss of FTO in mice resulted in a significant reduction of adipose tissue and lean body mass [17], and that FTO influenced adipogenesis by regulating events early in adipogenesis during the process of mitotic clonal expansion [19]. FTO mRNA was more highly expressed in RAS-treated groups than the control group, especially the DH group. After $60 \mathrm{~d}$, the highest FTO expression level was in the RAS-treated groups. Moreover, no significant difference was observed after $95 \mathrm{~d}$ between the GC and HC groups, or in their offspring. These results suggest that the effects of RAS supplementation on FTO expression are not heritable.

FTO is a nucleic acid demethylase that removes methyl groups from both DNA and RNA $[16,22]$. Previous studies have shown that DNA methylation is altered not only in oocytes of obese mice but also in their offspring [23]. The modification of DNA methylation provides a link between the environment and gene expression, therefore, we investigated the methylation levels of CpGs in the FTO promoter region. There are $15 \mathrm{CpG}$ dinucleotides present in the $2 \mathrm{~Kb}$ upstream of the start codon of FTO. BSP results showed that the CpG sites within the FTO promoter were highly methylated in all of the three groups (GC, HC, and DH). Although the methylation levels were not significantly different, our 
results revealed that promoter methylation and expression of FTO gene mRNA were negatively correlated. Thus, regulation by a methyl group blocking the transcription factor binding to this region (AC105989: 31,474-31,968 bp) is possible.

Previous study has demonstrated the polysaccharide of Angelica sinensis in ameliorating glucose and lipid metabolism disorders related to obesity, possibly due to interactions with insulin and serum inflammatory factors [8]. The molecular mechanisms, however, remained unclear. In the present study, the extent of the adipose tissues was different between $\mathrm{HC}$ and $\mathrm{DH}$ mice. We suggested that this difference in body weight may be caused by adipocyte morphology. Furthermore, we performed histological examination to view the alterations in adipocyte shape and size between $\mathrm{HC}$ and DH mice. As shown in Figure 4, adipocytes in the HC group were more mature and characterized by bigger lipid droplets, while those in the DH had more and smaller lipid droplets. The mice in the DH group fed RAS for $60 \mathrm{~d}$ showed much smaller adipocytes and more intercellular substance than $\mathrm{DH}$ mice fed RAS for $35 \mathrm{~d}$.

\section{Conclusion}

This study investigated whether RAS could suppress body weight in HFD obese mice. The supplementation of RAS was associated with suppression of body weight, increased FTO mRNA expression, and reduction of methylation. The present study provides new insights into the biological role of RAS. Further detailed analyses need to be performed to understand the mechanism of RAS in body weight suppression.

\section{Conflicts of Interest}

All authors declared that they have no conflicts of interest.

\section{Acknowledgments}

This study was supported by the grants from the Undergraduate Innovative Experiment Program of Sichuan Agricultural University (201410626007), the National Natural Science Foundation of China (31301945), and the Chinese Domestic Animal Germplasm Resources Infrastructure.

\section{References}

[1] A. Samuelsson, P. A. Matthews, M. Argenton et al., "Dietinduced obesity in female mice leads to offspring hyperphagia, adiposity, hypertension, and insulin resistance: a novel murine model of developmental programming," Hypertension, vol. 51, no. 2, pp. 383-392, 2008.

[2] M. van Heek, D. S. Compton, C. F. France et al., "Diet-induced obese mice develop peripheral, but not central, resistance to leptin," Journal of Clinical Investigation, vol. 99, no. 3, pp. 385390, 1997.

[3] C. Church, S. Lee, E. A. L. Bagg et al., "A mouse model for the metabolic effects of the human fat mass and obesity associated FTO gene," PLoS Genetics, vol. 5, no. 8, Article ID e1000599, 2009.
[4] D. Y. Lu, C. H. Tang, Y. H. Chen, and I. H. Wei, "Berberine suppresses neuroinflammatory responses through AMP-activated protein kinase activation in BV-2 microglia," Journal of Cellular Biochemistry, vol. 110, no. 3, pp. 697-705, 2010.

[5] J. Zhao, X.-B. Sun, F. Ye, and W.-X. Tian, "Suppression of fatty acid synthase, differentiation and lipid accumulation in adipocytes by curcumin," Molecular and Cellular Biochemistry, vol. 351, no. 1-2, pp. 19-28, 2011.

[6] L. Xiao, J. Zhang, H. Li et al., "Inhibition of adipocyte differentiation and adipogenesis by the traditional Chinese herb Sibiraea angustata," Experimental Biology and Medicine, vol. 235, no. 12, pp. 1442-1449, 2010.

[7] K. A. Fawcett and I. Barroso, "The genetics of obesity: FTO leads the way," Trends in Genetics, vol. 26, no. 6, pp. 266-274, 2010.

[8] K. Wang, P. Cao, W. Shui, Q. Yang, Z. Tang, and Y. Zhang, "Angelica sinensis polysaccharide regulates glucose and lipid metabolism disorder in prediabetic and streptozotocin-induced diabetic mice through the elevation of glycogen levels and reduction of inflammatory factors," Food and Function, vol. 6, no. 3, pp. 902-909, 2015.

[9] W. G. P. H.-Y. Hsu, Chinese Herb Medicine and Therapy, Aurora Publishers Incorporated, Nashville, Tenn, USA, 1976.

[10] C. Liu, J. Li, F. Y. Meng et al., "Polysaccharides from the root of Angelica sinensis promotes hematopoiesis and thrombopoiesis through the PI3K/AKT pathway," BMC Complementary and Alternative Medicine, vol. 10, article 79, 2010.

[11] W. Cao, X.-Q. Li, X. Wang et al., "Characterizations and antitumor activities of three acidic polysaccharides from Angelica sinensis (Oliv.) diels," International Journal of Biological Macromolecules, vol. 46, no. 1, pp. 115-122, 2010.

[12] S. Zhang, B. He, J. Ge et al., "Extraction, chemical analysis of Angelica sinensis polysaccharides and antioxidant activity of the polysaccharides in ischemia-reperfusion rats," International Journal of Biological Macromolecules, vol. 47, no. 4, pp. 546-550, 2010.

[13] T. M. Frayling, N. J. Timpson, M. N. Weedon et al., "A common variant in the FTO gene is associated with body mass index and predisposes to childhood and adult obesity," Science, vol. 316, no. 5826, pp. 889-894, 2007.

[14] L. Sanchez-Pulido and M. A. Andrade-Navarro, "The FTO (fat mass and obesity associated) gene codes for a novel member of the non-heme dioxygenase superfamily," BMC Biochemistry, vol. 8, article 23, 2007.

[15] A. Tiwari, S. M. Krzysik-Walker, and R. Ramachandran, "Cloning and characterization of chicken fat mass and obesity associated (FTO) gene: fasting affects FTO expression," Domestic Animal Endocrinology, vol. 42, no. 1, pp. 1-10, 2012.

[16] T. Gerken, C. A. Girard, Y.-C. L. Tung et al., "The obesityassociated FTO gene encodes a 2-oxoglutarate-dependent nucleic acid demethylase," Science, vol. 318, no. 5855, pp. 1469$1472,2007$.

[17] J. Fischer, L. Koch, C. Emmerling et al., "Inactivation of the FTO gene protects from obesity," Nature, vol. 458, no. 7240, pp. 894898, 2009.

[18] C. Church, L. Moir, F. McMurray et al., "Overexpression of FTO leads to increased food intake and results in obesity," Nature Genetics, vol. 42, no. 12, pp. 1086-1092, 2010.

[19] M. Merkestein, S. Laber, F. McMurray et al., "FTO influences adipogenesis by regulating mitotic clonal expansion," Nature Communications, vol. 6, article 6792, 2015. 
[20] K. J. Livak and T. D. Schmittgen, "Analysis of relative gene expression data using real-time quantitative PCR and the $2^{-\Delta \Delta C T}$ method," Methods, vol. 25, no. 4, pp. 402-408, 2001.

[21] E. S. Jungheim, E. L. Schoeller, K. L. Marquard, E. D. Louden, J. E. Schaffer, and K. H. Moley, "Diet-induced obesity model: abnormal oocytes and persistent growth abnormalities in the offspring," Endocrinology, vol. 151, no. 8, pp. 4039-4046, 2010.

[22] G. Jia, Y. Fu, X. Zhao et al., "N6-methyladenosine in nuclear RNA is a major substrate of the obesity-associated FTO," Nature Chemical Biology, vol. 7, no. 12, pp. 885-887, 2011.

[23] Z. J. Ge, S. M. Luo, F. Lin et al., "DNA methylation in oocytes and liver of female mice and their offspring: effects of high-fatdiet-induced obesity," Environmental Health Perspectives, vol. 122, no. 2, pp. 159-164, 2014. 

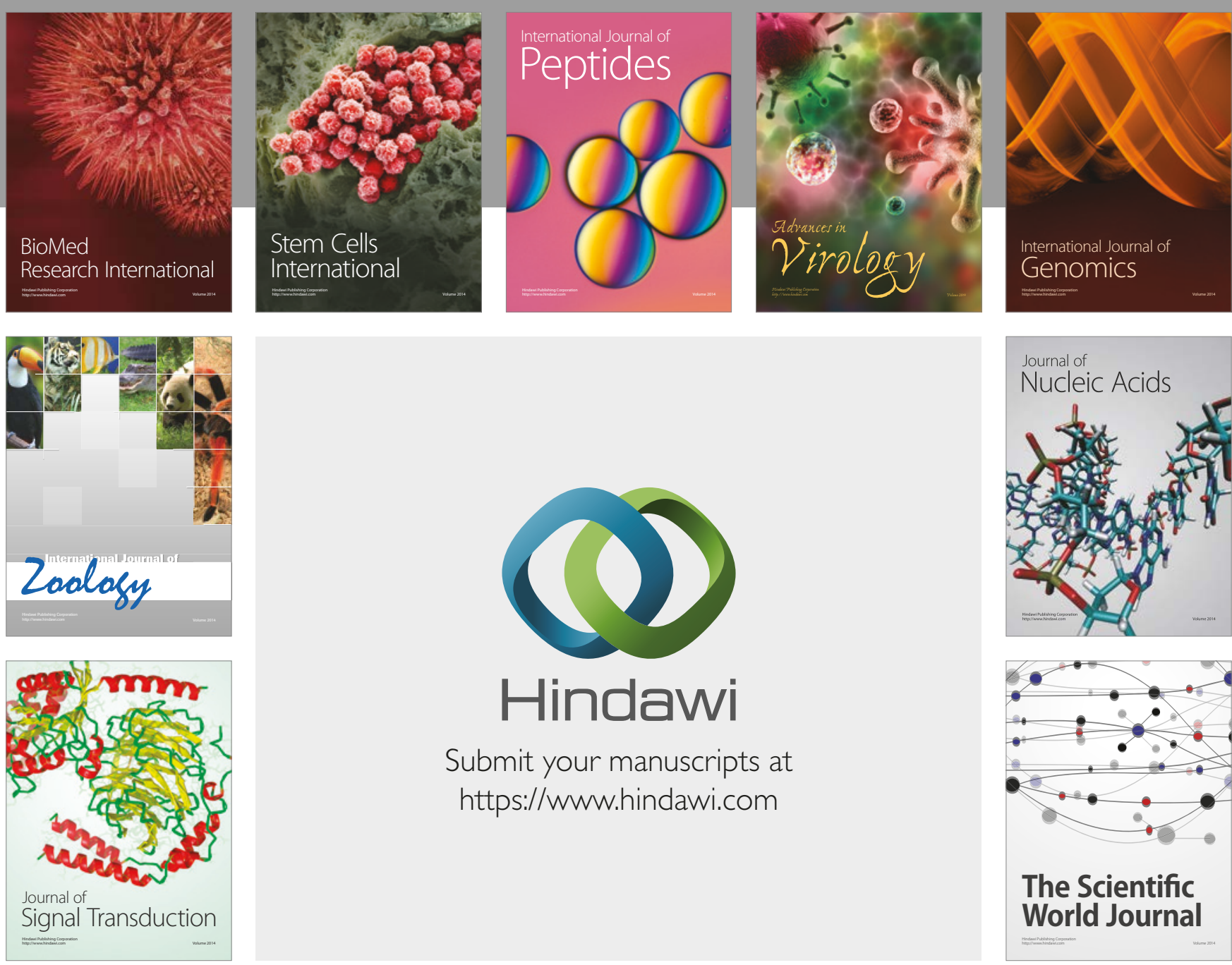

Submit your manuscripts at

https://www.hindawi.com
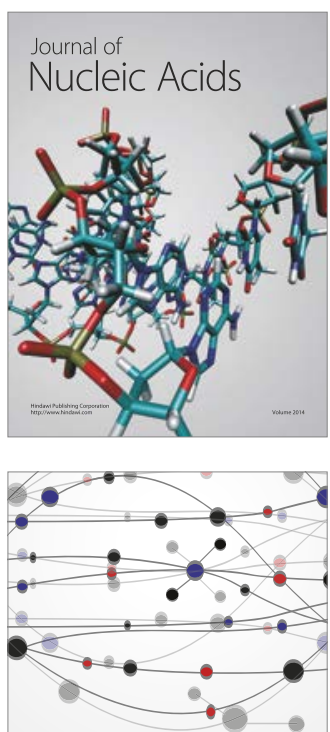

The Scientific World Journal

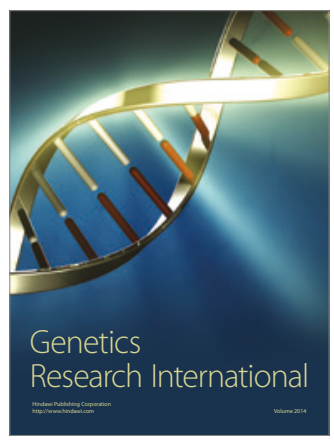

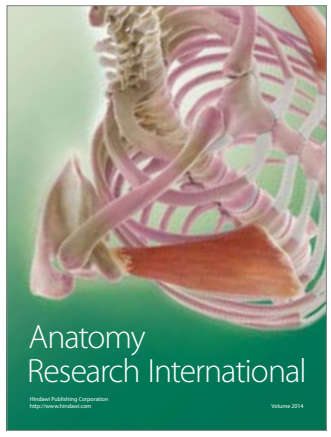

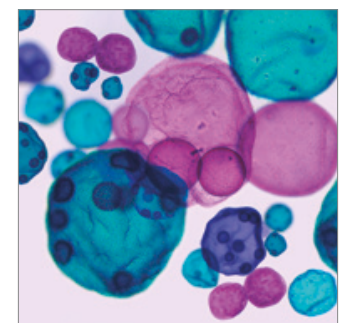

International Journal of Microbiology
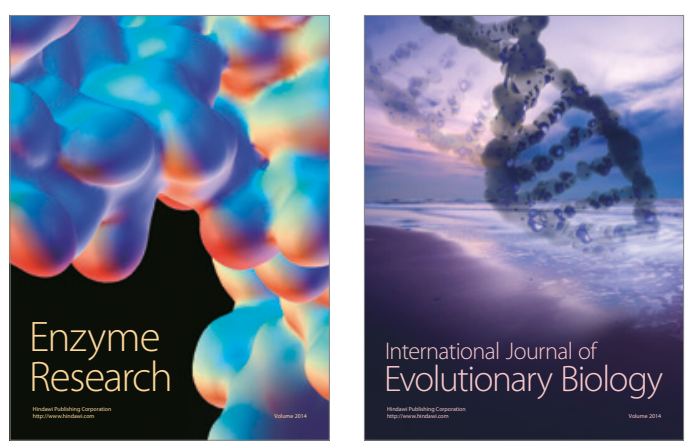
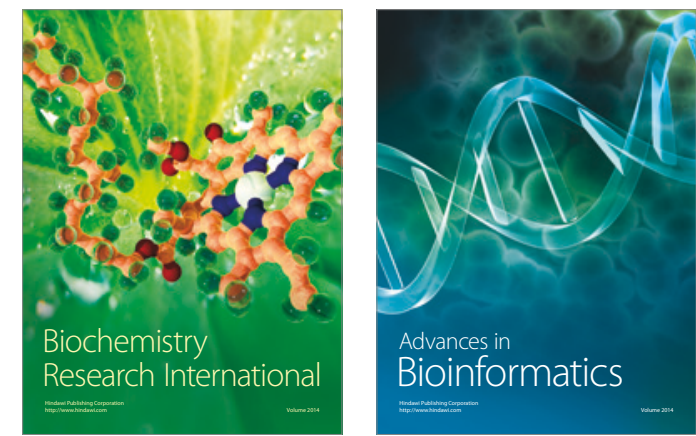

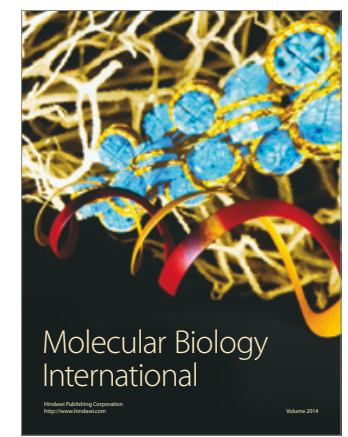

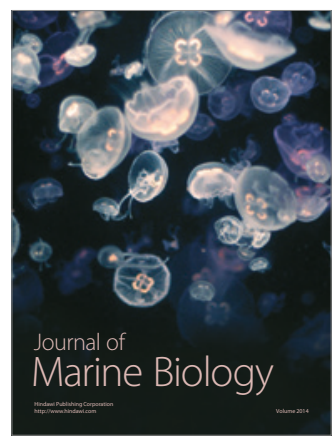

